\title{
The "Whole Language" Theory and Its Application to the Teaching of English Reading
}

\author{
Pan Ling \\ Foreign Languages Department, Shandong Institute of Business and Technology \\ 191 Binhai Middle Road, Yantai, 264005, China \\ E-mail: rebeccapanling@163.com
}

Received: October 24, 2011

Accepted: December 14, 2011

Published: March 1, 2012

doi:10.5539/elt.v5n3p147

URL: http://dx.doi.org/10.5539/elt.v5n3p147

\begin{abstract}
Based on a diagnosis of the problems in the traditional way of teaching English reading in China, this paper introduces the "whole language" theory and explores its application to the teaching of English reading. To begin with, it demonstrates the various problems in the teaching of English reading which severely prevent the improvement of English teaching. Then it introduces and elaborates on the "whole language" theory which brings new ideas and new methods to foreign language teaching. Finally it discusses how the "whole language" theory can be used to improve the teaching of English in general and English reading in particular.
\end{abstract}

Keywords: "Whole language" theory, English reading, Teaching

\section{Introduction}

Traditional methods of language teaching have dominated English teaching practices for a very long time in China. These theories and methods based on traditional grammar and microlinguistic s have paid too much attention to the teaching of one aspect of the English language while neglecting other aspects. To many teachers, the teaching of English means the teaching of English pronunciation, vocabulary and grammar; they forget about the cultural aspect of English. They are confined by the words-phrases-sentences pattern (that is, teaching the pronunciation and the usage of the word, explaining the phrases, analyzing and translating the difficult sentences)and seldom deal with larger units of language(Li Tingxing,1983). They isolate the language skills into listening, speaking, reading and writing, and teach them in isolation. These methods have led to many problems in the traditional teaching of English, especially in the teaching of reading.

With the emergence of macrolinguistics and the further development of relevant sciences like sociology and psychology, a more holistic view of language and language teaching has come into being. This is the "whole language" theory, which began to emerge in the middle of 1980's. The strongest point of this theory is that it regards language as a whole and thus avoids many problems in the traditional teaching methods. Based on an analysis of some of the major problems in traditional teaching, this paper will therefore introduce and demonstrate the "whole language" theory and explore its application to the teaching of English reading.

\section{The Major Problems in the Teaching of English Reading}

In order to improve the present situation of the teaching of English reading, we should first identify the problems or bad habits existing in the teaching and learning processes. Needless to say, there are bad habits on the part of both the teachers and the students.

\subsection{Problems of the Teacher}

\subsubsection{Grammar--oriented}

In the teaching of English reading, some teachers pay too much attention to grammar. This phenomenon is mainly caused by our present testing practices which is usually grammar-oriented. When the teachers teach English reading, they usually direct the students to analyze the grammatical points in the text and the exercises related to the text are usually grammar-connected. What the students get from the text are only some grammar rules. They make little progress in reading skills, let alone listening, speaking, writing, and other skills. If things go on like this, the students can only analyze grammatical points when they are given a piece of reading material, and the teaching will often be a great failure. 


\subsubsection{Vocabulary-oriented}

This is a same case with being grammar-oriented in essence. The teachers of this kind overemphasize the importance of vocabulary. When they deal with a text, the first and the most important thing to do is to teach new words, and explain their usage in the process of teaching the text. Though this may do some good to the reading, the effect is usually limited. The students taught in this way will get nothing but new words from the text. Their reading ability can not be improved effectively. Consequently, the teaching of reading will be likely unsuccessful. The students may have a very large vocabulary, but they can not communicate with the foreigners, nor can they understand a passage completely. We should clearly know that though vocabulary is very important, it is not the whole of reading.

The purpose of reading is to understand the passage well and to get useful information from it. If we just emphasize grammar or vocabulary and neglect the fact that language is a whole, it is impossible for us to understand the intention of the writer completely. Most of the information we get may be irrelevant. Grammar and vocabulary are just the necessary means of reading, but they are not the ends of reading.

\subsection{The Problems of the Students}

While we analyze the teacher's teaching problems, we should also realize that there are also some bad reading habits on the part of the students which will doubtlessly hinder their effective understanding of the reading materials. In the following parts, we will discuss some of them.

\subsubsection{Slow Reading}

Some students tend to think that the more slowly we read, the more exactly we comprehend. Some even read the text word by word. But psychological findings show that reading speed has very little to do with the degree of comprehension. On the contrary, experiments show that the reader who reads fast is more capable than the slow reader in grasping the main idea of the passage(Genesee,1994).

\subsubsection{Vocalising}

Vocalising means reading with pronunciation. The main cause of it is that the students lack training in silent reading. Experiments show that the speed of reading with vocalising is far slower than that of silent reading, and it also affects the comprehension of the passage.

\subsubsection{Mental Translating}

Mental translating means that when a reader reads a passage, he tries to understand it by translating it from English into Chinese. This is a common mistake that foreign language learners make when they read. If a student translates while he reads, he will easily ignore the meaning of the whole passage, but only pay attention to the translating of the single sentences.

\subsubsection{Being Too Dependent on Dictionaries}

This refers to the frequent use of dictionaries during the course of reading. We can imagine how slow it is. What is more, the reading of the whole passage is interrupted because of the frequent use of dictionaries. So is the understanding of the information of the passage.

These bad habits of both the teacher and the students have bad influences on the teaching of English reading and reading comprehension. They destroy the integrity of language because it is very easy for the people who have them to pay too much attention to one or some aspects and fail to see that language should be taught and learnt as a whole. The "whole language" theory is a brand-new theory which can help to correct these bad habits. It advocates that the teacher should teach the language as a whole. The following parts of this paper will introduce this new theory and explore its application to the teaching of English reading.

\section{The "Whole Language" Theory}

The "whole language" theory was advocated in the middle of the 1980's and became fashionable for a time in the educational world of America, and it is still popular nowadays. At the very beginning, it was mainly used to deal with the study of the mother tongue, but since the 1990's, it began to be used in foreign language teaching(Hedgecock, Jogn\&Sandra,1994). Rigg, Freeman and Freeman, Hedgecock and Pucci, Redman and Adair-Hauck all wrote papers and works to discuss how to apply this theory to the teaching of English as a second language(Tang, Lixing,1998). What is the "whole language" theory then? What are its basic principles and theoretical basis? How is it used in language teaching? We will discuss these questions in the following sections.

\subsection{The Theoretical Basis and Principles of the "Whole Language" Theory}

\subsubsection{Theoretical Basis}

According to educational psychologists, in order to let the students get perceptual knowledge and clear ideas, the 
teacher should guide the students to conduct a careful study of the passage that they are going to learn; and then the teacher should guide the students to study every part of the passage and the relationships among the parts. Finally the students will have a clear idea about the object of study concerned. This process is the theoretical basis of the "whole language" theory.

\subsubsection{Principles}

It is very difficult to define the "whole language" theory in one or two sentences. But one point we should pay attention to is that the "whole language" theory is not merely a kind of teaching method or a kind of teaching skill, but a whole theory about language teaching, a set of principles directing classroom teaching.

\subsubsection{The Directing Principle}

This theory puts the overall understanding of the whole text in the first place and regards the students as the center of classroom teaching. The basic pattern of teaching is "whole (the understanding of the whole text on the surface) - parts (the study of language points) - whole (the deep understanding of the text as a whole)". The final aim of teaching is the comprehension of the whole passage. Giving various exercises, the teacher tries to combine pronunciation, vocabulary and grammar into an organic whole (Spruman \& Cardyn V, 1992).

\subsubsection{The Basic Principles}

Language is a whole. Here the "whole" is not merely the sum of all the parts, but is greater than this sum. The parts of language (pronunciation, grammar and vocabulary, etc.) have no meanings when they are isolated from each other(Freeman, Tvonnes \& Freeman, 1992). Language should not be separated into pronunciation, grammar and vocabulary. Goodman, one of the chief advocators of the "whole language" theory, points out that though speaking occupies a very important place in children's language ability, it is untrue that the comprehension ability and reading and writing ability are not developed until the speaking ability is fully developed. In fact, these abilities develop side by side with the speaking ability (Goodman\&Kenneth,1991). Therefore, language teaching should begin with dealing with the whole and then transit to the parts gradually. It is unwise to develop listening, reading, speaking and writing abilities separately.

Language teaching should take the students as its core. Language is the tool of communication and is the medium of thinking. Language learning is not a passive, mechanical process in which the students imitate language behavior, but a process in which the students communicate with each other and exchange ideas in the language they learn, and discover and generalize language rules. In this language learning process, the students master a new language on the basis of the comprehension of the known one. They put the emphasis on the whole understanding, but not merely on the understanding of the parts. Therefore, the teacher should take the students' needs, aims, and interests of learning into consideration when they teach and try to arouse the students' interest. What is more, the teacher should direct the students to use the language with positive aims and to direct the students to transfer the emphasis from studying the whole to studying the parts after they get the whole understanding.

Language knowledge and abilities should be cultivated in natural language environment. Traditional language teaching mainly cultivates language knowledge (pronunciation, grammar and vocabulary) and basic language abilities (listening, speaking, reading and writing) separately. It insists that language knowledge and language skills should be taught from the easy ones to the difficult ones. This violates the natural law that the students follow in learning a language. This is not an effective way of learning language. The famous psychologist Piaget points out that people's language ability is developed gradually during the course of probing the world actively (Tan, xiugui, 1996). The famous Russian psychologist found that people obtain language ability through communicating and exchanging ideas in language with other people. Therefore, the "whole language" theory insists that only by putting language knowledge and language abilities into rich, real, natural language environments can the students gradually and actively master the language, including language knowledge and language abilities.

The teacher should have confidence in the students and spur the students to fully bring out their latent potentials. The "whole language" theory holds the view that in language teaching, the teacher should not only be a knowledge-passer, but also be a planner, an encourager and an enlightener. By doing this, the teacher can arouse the students' motive power and interest to the optimum condition. Vygetsky points out that in communicative activities, the students should use language actively and naturally through which they can improve their language ability. Therefore, having full confidence in the students, creating rich, natural and easy environments, providing them with enough demonstrations of the whole language are some very important aspects in "whole language" teaching.

\subsection{The "Whole Language" Theory in China}

Though the "whole language" theory has been popularized and debated on for more than ten years in America, China` educational world pays little attention to it. Only a few experts wrote articles to introduce this theory in the 
past several years. "It is really a pity that the foreign languages teaching in china pays little attention to the theory which has caused sharp argument and exerted great influence abroad" (Genesee\&Fred,1994). The foreign language teaching in our country has reached the period of the communicative method. The "whole language" teaching has some similarities to the communicative method. Therefore, some principles of it can be used in our country's foreign language teaching. For example, the "whole language" theory pays more attention to the integrity of language than the communicative method. Taking the aims, motives and environments of learning foreign language into consideration, we can develop the students' listening, speaking, reading and writing abilities at the same time. One point we should notice is that not all of the principles of the "whole language" theory are suitable for our foreign language teaching. A never outmoded principle of dealing with any new teaching theory is to adapt, but not to adopt.

\section{The Application of the "Whole Language" Theory to the Teaching of English Reading}

Being a teaching theory, the "whole language" theory can of course be used in language teaching. We will discuss its application to the teaching of English reading below. There are seven teaching skills and methods derived from this theory.

\subsection{Teaching the Language as a Whole}

In traditional language teaching, the teacher always teaches pronunciation, grammar and vocabulary separately. But in the "whole language" classroom, the teacher does not do so. The teaching emphasis lies on the meaningful whole language activities, for example, listening to the text, comprehending the content of the whole text, discussing the main idea of the text, etc. Instead of keeping the traditional "word-sentence-passage" order, the "whole language" teacher starts the teaching from reading and undersrtanding the whole passage. In this process, the students not only cultivate the comprehending and thinking ability, but also cultivate their overall language abilities. The grammar rules, usage of words are not going to be taught systematically, the teacher can teach them at any point of time in the teaching process. For example, when there is a pronunciation problem in the text, the teacher can add some knowledge about phonetics; when passive voice appears several times successively in the text, the teacher can grasp this chance to ask the students to discuss this grammatical point, and provide more examples to illustrate it. In short, in the teaching of English reading, the teacher should lay the emphasis on the comprehension of the whole passage, and at the same time, give consideration to the study of grammar, vocabulary and pronunciation.

\subsection{Student-centeredness}

The "whole language" teacher analyses the need and interest of the students and take the analysis as the basis of setting teaching aims, choosing reading meterials and making teaching plans.

Though the teacher provides the students with a lot of demonstrations of the language points, he tries to play a new role in organizing and leading in group activities, discussing, reading and writing together with the students. In the process of teaching of English reading, the teacher can ask the students to discuss the text in groups and he just plays a directing role. He can encourage and guide the students to comprehend the text, study the new language points, including grammar and the usage of the words. Thus an important characteristic of "whole language" teaching is student-centerdness, which means that the teaher gives the students the chance to search, to get to know, and to summarize. Student-centerdness also means giving the students more choice for study, for example, selecting the books they like to read, writing about the subject they want to write about, etc. In the process of teaching reading with English as a foreign language, the teacher should pay attention to the cultural comparison between English and Chinese. The "whole language" teacher knows that culture is a very important part of the language. This kind of cultural comparison can help the students to understand the text better.

\subsection{Teaching Language in Context}

The "whole language" teacher thinks that the teacher should make full use of contexts to cultivate the students' language ability. In the "whole language" teaching classroom, mechanical practice of sentence patterns will not be found. The understanding of the text in its context can help the students to understand it as a whole. In the teaching of reading, the teacher should provide more chances for the students to do some contextual comprehension practice. The teacher can put this into reality by questioning, discussing, retelling the text, etc. Another way to realize this is to ask the students to create and design the situational context and do some writing. A reader gets nothing but some fragmented information from the passage if he ignores the comprehension of it in its concrete context. Chinese students tend to make this mistake. They always pay attention to the comprehension of some special words, sentences and paragraphs, but seldom take the passage as a whole. This often leads to their one-sided comprehension of the text. 


\subsection{Literature-basedness}

In the "whole language" teaching, the broad-sense of "literature" includes stories, novels, poems, plays, allegories, letters; arguementations and the articles about mathematics, physics and chemistry, etc. The simplified graded basic readers used in the traditional language teaching are regarded as inappropriate because they lack the authenticity and taste that they have originally. This is caused by the fact that vocabulary and language structure are under the artificially imposed control, which leads to another bad influence that language itself becomes stiff and incomplete. For this reason, it is very difficult for Chinese students to get the implied information which they can get if they read the original. The main purpose of reading is to get information from the article, but the simplified ones prevent the reader from that. In the "whole language" teaching classroom, the teacher has a large quantity of readers with various subject matters and different grades at hand for themselves as well as for the students to read. These readers are chosen carefully. The teacher should collect the articles which are not only meaningful but also embody some language knowledge. Only by doing this can the students develop in all aspects.

\subsection{Focus on Talk}

The "whole language" teaching emphasizes the ability of oral expression, the ability of communication, the ability of thinking and the ability of analysing (Goodman \& Kenaeth, 1991). Therefore, in the teaching of reading, retelling the story, discussing the context and characters of the story, performing a play are all the frequently-used techniques by the "whole language" teacher. Through these activities, the students not only improve the ability of oral expression, but also deepen their comprehension of the text.

\subsection{Integration with Writing}

In the teaching of reading, the "whole language" teacher encourages the students to write frequently on the text that they learn. Through rich writing, the students can set up close relationship between the pronunciation and the spelling of English as well as the relationship between oral English and written English. By this means, writing can help the students to deepen the comprehension of English language and texts, and the students can accumulate language knowledge. The subject matter and the type of writing are various. They can be stories, diaries, poems, letters and essays. The teacher lays stress not only on the writing content and the result, but also on the process. The writing can be done both in class and after class. Through writing, the students learn and use English to communicate with others and express their ideas. At the same time, writing can cultivate the students' enthusiasm and desire (Tang, Lixing, 1998).

In the "whole language" teaching classroom, cooperative learning is frequently used, especially in the reading class. The teacher always tries to cultivate a conducive learning atmosphere in which the students help each other and exchange knowledge with each other. For example, in a class of 30 students, the teacher can divide the students into five or six small groups. Each group can read the same or different texts, discuss the content and the main idea, answer questions about the text and do some exercises of language ability. Then these small groups blend into a larger group and share what they have learnt from the study. This kind of activities can form a lively, meaningful environment of language learning in which the students can learn and use English actively and freely. This method enforces the students' confidence and cultivates their ability of independent learning and their cooperative spirit (Goodman\&Kenaeth,p.249). This makes the students become the masters of themselves in their study.

\subsection{Informal Assessment}

In the "whole language" teaching classroom, the assessment of improvement is meaning-centered and student-centered. The assessment and examination of the "whole language" teaching are viewed in the light of the whole. The "whole language" teacher thinks that the students can not be assessed by the traditional way of examination, which is regarded as the only criteria to measure the students' study. They are inclined to use informal assessment. For example, they observe the behavior of the students in class and evaluate the quality and quantity of their homework, or they gather the writings of the students in a portfolio, or give evaluation on the students' reading activity. Finally, they give the students a synthetical evaluation on their study, not only a score from examinations. In our county, the popularized way of assessing the reading ability is to take an examination. The students' reading ability is evaluated only by the marks he gets in the examination which is composed of only several articles. The student who gets a high mark is believed to have mastered English well. This is rather one-sided.

In the "whole language" teaching classroom, the teacher usually uses all of these principles at the same time in one period when they teach English reading. Is it good? Opinions vary and no unanimous conclusion can be drawn.

\section{Conclusion}

Like every influential educational theory, the "whole language" theory has caused sharp argument in the American educational world at the very beginning, and the argument is becoming sharper and sharper in the last ten years. 
Some people advocate it greatly and some criticize it fiercely. Of course, it has its own advantages and disadvantages. The advantages lie in three aspects. Firstly, with this theory, it becomes easier and more possible for the students to understand the whole text. Secondly, it blends the practices of listening, speaking, reading and writing into an organic unity, avoiding developing the reading ability only in the teaching of English reading. Thirdly, it adopts informal assessment so that the students can get a more objective score.

The disadvantages lie in two aspects. Firstly, the teaching of grammatical rules lack systematization. According to this theory, the grammatical rules are taught only when they appear. So some grammar rules that seldom appear in the text will be easily ignored. Secondly, the word spelling and pronunciation rules are important links in the process of improving the reading ability, but the "whole language" theory pays little attention to them.

In my opinion, its advantages overweigh its disadvantages and it is a theory that is worth popularizing. The advocators are beginning to accept some criticisms and making some efforts to improve and enrich its principles. I think with continuous improvement, it will become more satisfactory.

From the above analysis, we can draw the following conclusion. Firstly, there exist a lot of problems in our teaching of English reading, and they severely affect the improvement of our English teaching. Secondly, the "whole language" theory brings new ideas and new methods to our foreign language teaching. We can use it to improve the teaching of English reading. Thirdly, the "whole language" theory has both advantages and disadvantages, and its advantages overweigh its disadvantages, but it still needs further improvement.

\section{References}

Freeman, Tvonnes, \& David E. Freeman. (1992). Whole language for second language learners Portsmouth. NH: Heineman. pp. 215

Genesee. Fred. (1994). Some holes in whole language. TESOL matters, Vol. 4, 45

Goodman, Kenneth (1991). What's whole in whole language. Nassachusetts: Basic Blackwell Ltd. pp. 123

Hedgecock, Jogn, \& Sandra Pucci. (1994). Whole language application to ESL in secondary and higher education in the FLES classroom: adapting strategies to teach reading and writing. Foreign Language Annual, Vol. 27, No.3, 42

Li Tingxing. (1983). English pedagogy. Peking: High Education Press. pp. 306-4

Tang Lixing. (1998). The theory and application of the "whole language". The English Teaching and Researching in Junior Middle School journal, Vol.10, No.1, 2

Spruman, Cardyn V. (1992). Whole language questions: what teachers are asking. Contemporary Education, Vo1.64, No.1, 19

Tan, Xiugui. (1996). Remarks on the whole language. Foreign language world journal, No. 6, 40 